\title{
Tree is Life: uma aplicação no auxílio da restauração de conflitos entre arborização e equipamentos urbanos
}

\author{
Savio Guedes Amaral ${ }^{1}$, Lizandro Pereira de Abreu ${ }^{1}$, Felipe Gonçalves dos Santos $^{1}$ \\ ${ }^{1}$ Instituto Federal de Educação Ciências e Tecnologia do Piauí - Campus Corrente \\ savioguedes89@gmail.com, lizandro.abreudifpi.edu.br, \\ felipe.santosdifpi.edu.br
}

\begin{abstract}
Due to the problems triggered by the lack of planning in urban afforestation, this work aims to use technology to assist the population and the competent bodies in maintaining these problems in a practical and efficient way. The study was developed in three stages and shows the tool called Tree Is Life as a technological method in proposing improvements in afforestation. The application proved to be a support of paramount importance in combating existing conflicts between urban equipment and the afforestation of public places, in addition to presenting several advantages over similar apps.
\end{abstract}

Resumo. Devido aos problemas desencadeados pela falta de planejamento na arborização urbana, este trabalho objetiva por meio do uso da tecnologia auxiliar a população e os órgãos competentes na manutenção dessas problemáticas de forma prática e eficiente. $O$ estudo foi desenvolvido em três etapas e mostra a ferramenta intitulada de Tree Is Life como método tecnológico na proposição de melhorias na arborização. A aplicação se mostrou como um suporte de suma importância no combate aos conflitos existentes entre equipamentos urbanos e a arborização de logradouros públicos, além de apresentar diversas vantagens em relação a apps semelhantes.

\section{Introdução}

O processo de urbanização tem desencadeado cada vez mais problemáticas ao meio ambiente decorrente principalmente do aumento populacional. Consequentemente, tem sido necessário adotar determinadas medidas para tornar cada vez melhor os ambientes urbanos. Métodos como a arborização urbana são comumente usadas nas cidades com a finalidade de melhorar as condições humanas e ambientais.

Segundo a Companhia Paranaense de Energia (2009) relata arborização urbana como, vegetações que pertencem a todo perímetro urbano. É um dos recursos mais influentes no ecossistema das cidades. Basicamente, a arborização urbana é dividida em áreas verdes (parques, bosques, praças e jardinetes) e arborização de ruas (vias públicas).

Arborização urbana apresentam necessidades de manutenção pois sofrem constantemente de queda das suas folhas, flores e frutos além de determinados conflitos com os instrumentos urbanos, tais como, interferência na rede elétrica e provocando rachaduras em calçadas e muros. Mediante essas interferências provocadas por falta de planejamento na arborização urbana que se faz necessário o uso de tecnologias que vise auxiliar na manutenção e correção desses problemas. 
Por meio de parcerias entre professores do curso de tecnologia em Gestão Ambiental e professores e alunos do curso de tecnologia em Análise e Desenvolvimento de Sistemas do Instituto Federal do Piauí - Campus Corrente, visando a melhoria o ambiente das metrópoles, dando ênfase as infraestruturas das cidades, foi proposto desenvolver uma aplicação que facilitasse a comunicação entre população e os órgãos responsáveis, servindo como intermédio entre eles.

Em razão ao que foi apresentado, esse artigo tem como objetivo apresentar uma ferramenta que auxilia os habitantes nas situações de interferências causadas pela arborização urbana, tendo como ênfase o bem estar tanto da população como do meio natural, tornando mais rápido e prático a comunicação entre a população e os órgãos responsáveis. Assim, proporcionando melhores precisão em sentido de localização e informação acerca do conflito provocado visando, principalmente, a manutenção desses ambientes.

\section{Trabalhos Relacionados}

No trabalho feito por de Lucena (2019), foi implementado um software de governança que auxilia o cidadão a relatar os problemas urbanos encontrados em seu dia a dia. Com o aplicativo os responsáveis por resolver tais problemas poderão tomar providências adequadas a real situação do mesmo, uma vez que as informações disponíveis no relato serão precisas, reais e atuais. Foi implementado com a linguagem de programação Java Script e com o framework Node.js. O resultado final apresentado foi uma aplicação híbrida, sendo acessada via web e em plataformas mobile.

A aplicação Pelas Ruas, tem como principal objetivo enviar uma foto e descrição do problema encontrado. É uma plataforma colaborativa em que usuários discutem e compartilham problemas urbanos em Porto Alegre e região, essa iniciativa foi realizada em conjunto pela Gaúcha, Zero Hora e RBSTV.

O aplicativo Prefeitura 360 desenvolvido por Caique Soares (2019), nela funciona com série de categorias para cada problema. Seu objetivo é relatar problemas urbanos diretamente para a prefeitura, enviando fotos, localização, descrição do problema encontrado, outra funcionalidade encontrada foi em responder pesquisas e acompanhar notícias da cidade.

\section{Tree is Life}

Na primeira etapa de desenvolvimento do Tree is Life o projeto contou com os professores de informática e de gestão ambiental, que realizaram os levantamentos de quais seriam as principais interferências causada pela arborização urbana, tais elas: interferência de árvores em redes elétricas, rede telefônicas, iluminação pública, sinalização de trânsito, interferência causadas por raízes (calçadas, muros...), inclinação das árvores, e podas drásticas.

$\mathrm{Na}$ segunda etapa foram realizadas várias séries de levantamentos de requisitos, e o estudo de quais seriam as melhores ferramentas utilizadas para o desenvolvimento da aplicação, tendo em vista a tecnologias mais recentes, e nos conceitos apresentados em sala. E na terceira e última etapa foi a implementação do projeto, e no desenvolvimento do aplicativo em paralelo com website, onde foi hospedado na nuvem, juntamente com o banco de dados, o aplicativo foi desenvolvido tanto para android como IOS, onde será vinculado com o banco de dados. 


\subsection{Arquitetura e Tecnologias}

O aplicativo conectará com a API para que os dados sejam salvos no banco de dados hospedado na nuvem, quando for solicitado uma reclamação. O controle dessas reclamações será feito pelo administrador do sistema, que ficará responsável por entrar em contatos com os órgãos responsáveis. A Figura 1 relata a arquitetura e Funcionamento do Tree is Life.

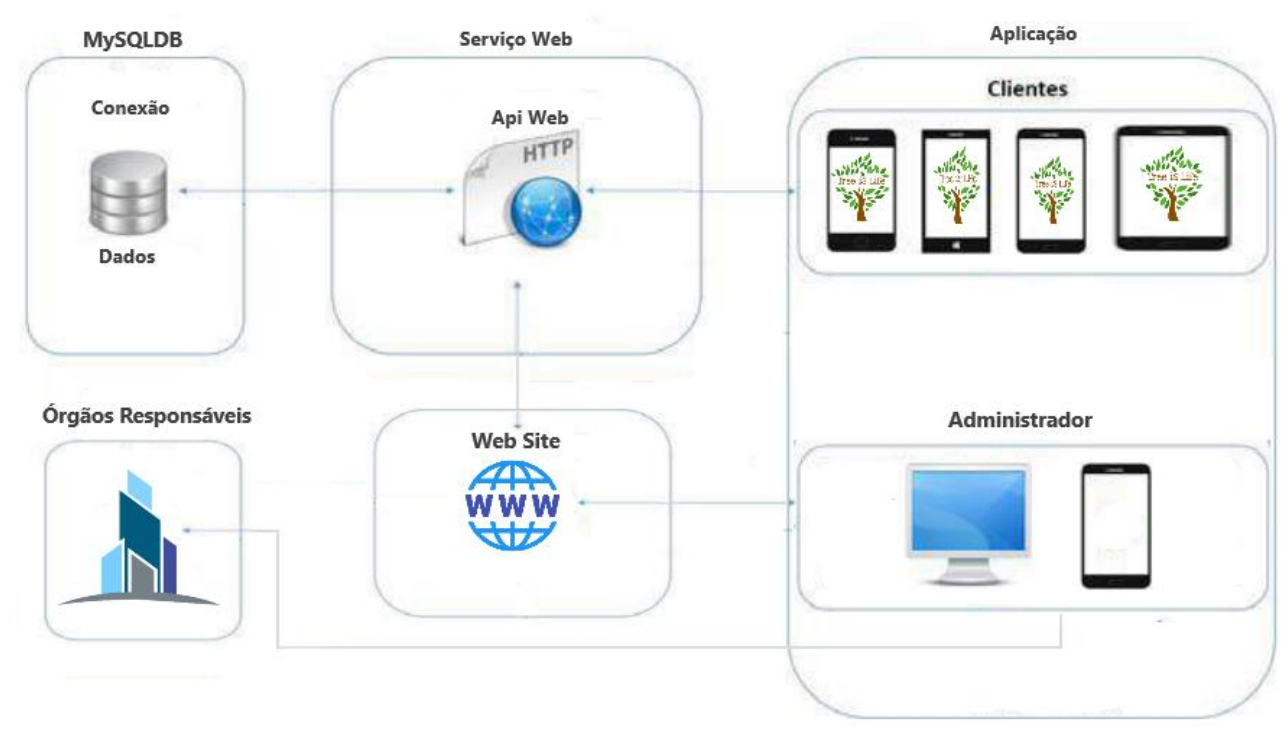

Figura 1: Arquitetura e Funcionamento do Tree is Life.

Para o desenvolvimento da aplicação foi utilizado um framework para dispositivos móveis denominada de Flutter. Utilizando um banco de dados distribuído hospedado na nuvem denominado como Mysql, que será acessado através de uma API pela aplicação mobile. O controle do sistema será feito pelo website. Para a implementação do mesmo, teve como base a linguagem de programação PHP.

De acordo com o blog Takeblog o conceito de API (Interface de Programação de Aplicações) está relacionado a um conjunto de rotinas e padrões estabelecidos por um software para a utilização das suas funcionalidades por outros aplicativos. Nada mais é do que uma forma de comunicação entre sistemas.

O framework Flutter foi desenvolvido pela Google e se trata de um kit de ferramentas de interface, onde fornece uma série de componentes visuais e funcionais para o desenvolvimento de aplicativos híbridos, pois com um único código e permitindo que seja compilado tanto para Android como IOS.

O Flutter apresenta um intermediário (bridge) entre a UI e o dispositivo, ele se encontra na camada do UI (User Interface) e não chama os componentes nativos do SO, ele é desenhado exatamente em um canvas que aumenta a performance e fluidez a nível de um aplicativo desenvolvido exclusivamente nativo. Além do ganho com performance o Flutter é uma tecnologia recente de fácil aprendizado e já possui alguns recursos sendo desenvolvidas, por esses motivos que ele foi escolhido ao invés do React Native.

Segundo Pisa O MySQL é um sistema gerenciador de banco de dados relacional de código aberto usado na maioria das aplicações gratuitas para gerir suas bases de dados. $\mathrm{O}$ serviço utiliza a linguagem SQL (Structure Query Language - Linguagem de Consulta Estruturada), que é a linguagem mais popular para inserir, acessar e gerenciar o conteúdo armazenado num banco de dados. 
O PHP é uma linguagem de programação de script open source (código aberto) de uso geral, bastante utilizada atualmente, especialmente utilizada para desenvolvimentos web, que pode ser utilizada em conjunto com a linguagem de marcação de hipertexto (HTML) juntamente com javascript e css.

\subsection{A aplicação (Tree is Life)}

Esse aplicativo tem como principal característica marcar pontos geográficos no mapa que são cadastrados pelo usuário permitindo que o mesmo possa reclamar pontos cadastrados por outros usuários (funcionando com o like do Instagram), quanto maior o número de reclamação mais prioridade ela possui.

\subsubsection{Mobile (Tree is Life Mobile)}

O aplicativo mobile é constituído por três abas de fácil navegação e de simples usabilidade facilitando o entendimento de usuários leigos. Na primeira aba da aplicação exibirá todos os pontos marcados por todos os usuários. A segunda é a aba da reclamação e a terceira e sobre o aplicativo.

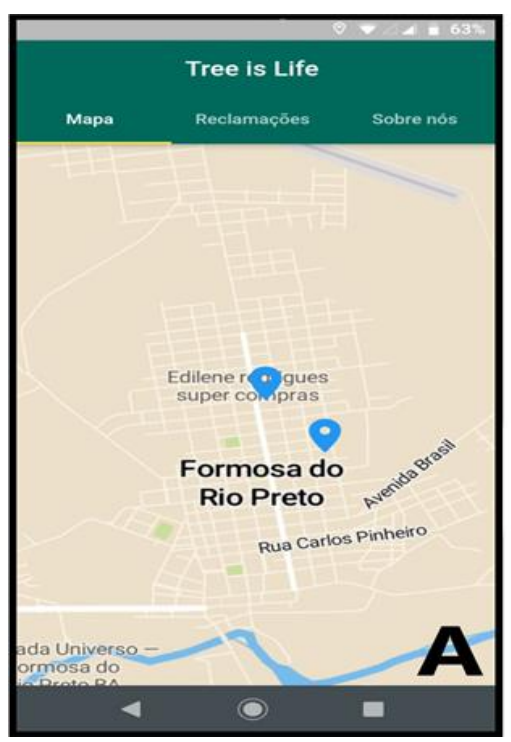

Figura 2.A - Página inicial do aplicativo, onde será exibido todos os pontos que foram marcados pelos usuários do aplicativo.
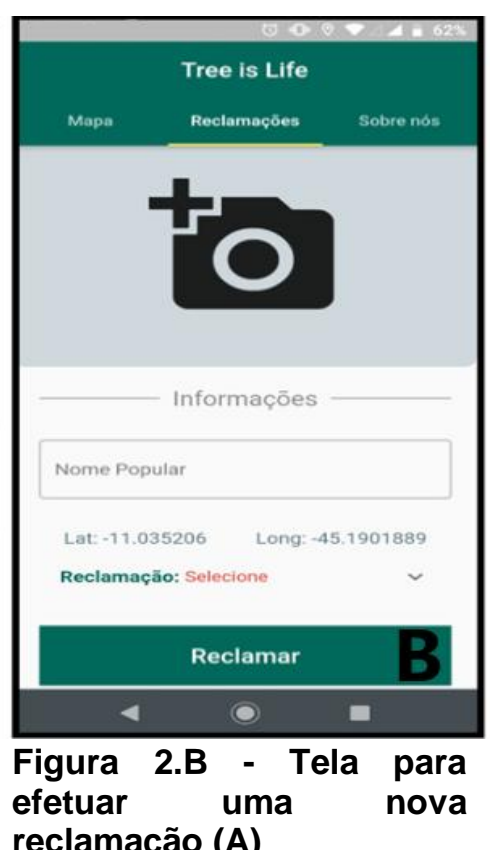

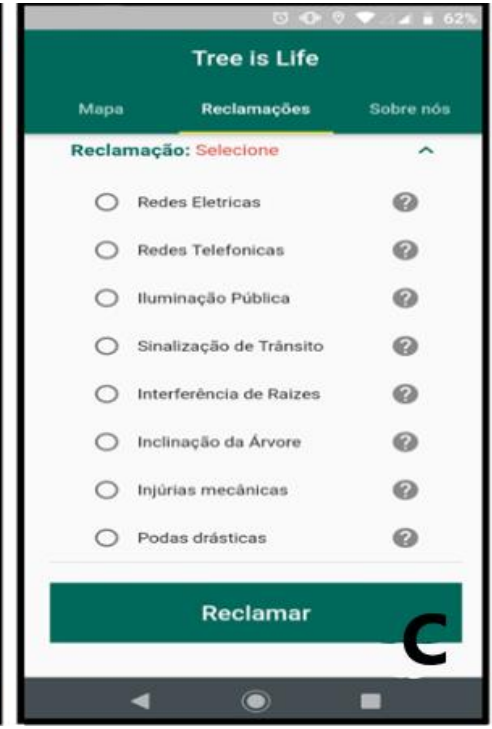

Figura 2.C Tipos de

Reclamações em que os problemas se encaixam (B)

A Figura 2.A mostra a tela inicial do aplicativo. Na primeira aba ao clicar em um ponto marcado a aplicação exibirá os detalhes da reclamação, contendo as fotos que foram tiradas, quantidades de reclamações feitas pelos usuários, o tipo de reclamação e o nome da arvore caso o usuário tenha informado.

A Figura 2.B. Retrata a tela para efetuar uma nova reclamação. Na segunda aba está relacionada às reclamações que serão cadastradas no sistema. Para cadastrar uma reclamação o usuário deverá tirar fotos do ocorrido, caso saiba o nome (popular ou científico) da árvore pode ser relatado, a latitude e a longitude serão preenchidas automaticamente. O tipo de reclamação é obrigatório, a Figura 2.C mostra tipos de reclamações, caso o usuário não saiba 
em qual tipo a interferência se enquadra o problema, ao lado de cada opção possui o ícone de ajuda, onde terá exemplos e o seu conceito.

\subsubsection{O website (Tree is Life Web)}

O sistema web desenvolvido com PHP servirá como controlador do sistema onde o administrador será responsável por controlar todas as reclamações feitas pelo aplicativo. Primeiro passo para iniciar o website, o usuário deve possuir um navegador web e suas respectivas credenciais necessárias para acessá-lo. É obrigatório a identificação, como o nome do usuário e sua senha.

Ao logar no sistema o administrador poderá realizar todos os controles das reclamações que foram feitas pelos usuários. A Figura 3.A mostra o mapa com os pontos marcados exibidos no website. Será listada no mapa os pontos geográficos marcados pelo aplicativo, cada ponto possuirá uma cor, tais elas como, verde (pequeno número de reclamações de 1 a 30), amarelo (número médio de reclamações de 31 a 70) e o vermelho (grande número de reclamação de 70 adiante).

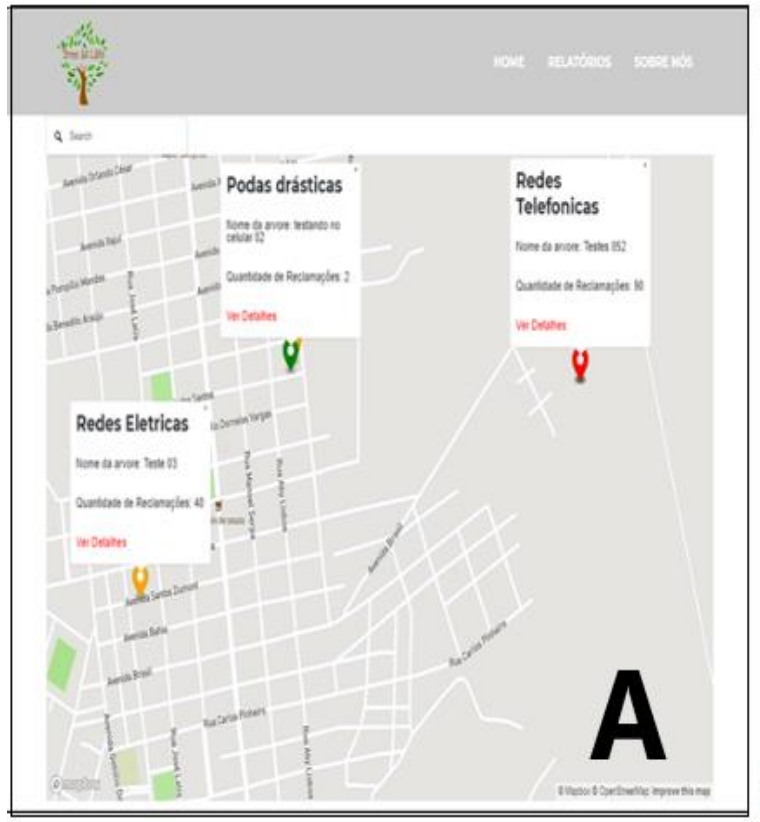

Figura 3.A - Mapa com os pontos marcados exibidos no website do Tree is Life.

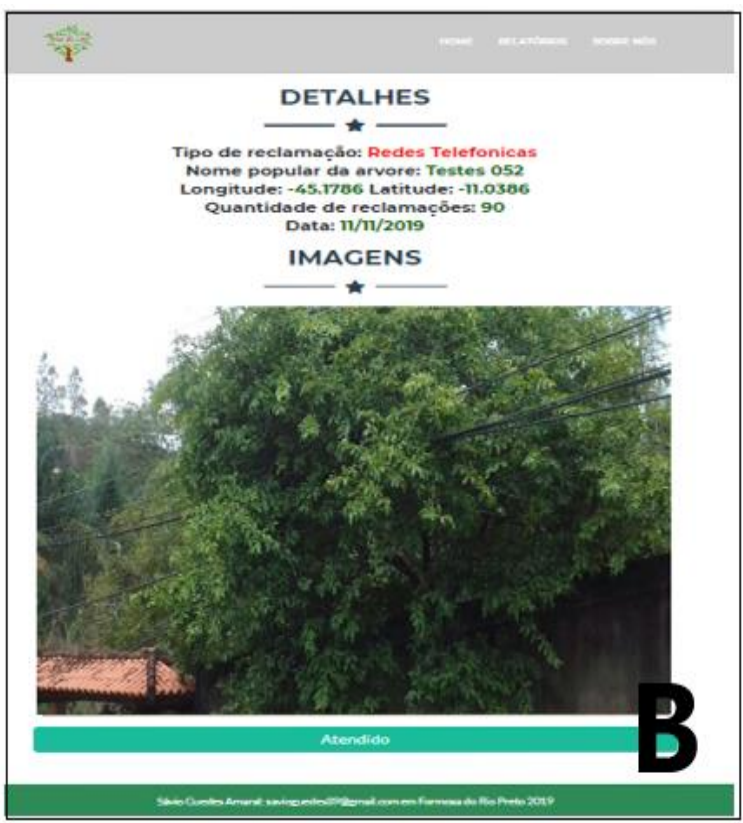

Figura 3.B - Detalhes dos problemas pressentem no website do Tree is Life.

Cada marcador geolocalizado possui detalhes, apresentando o tipo de reclamação, o nome popular da árvore, a quantidade de reclamações, e, as imagens de cada reclamação. A Figura 3.B ilustra detalhes dos problemas pressentem no website. Após o atendimento realizado pelos órgãos responsáveis o administrador pode dar baixa do problema cadastrado no sistema. $\mathrm{O}$ administrador também poderá visualizar relatórios dos problemas que foram atendidos.

\section{Resultados e discussão}

Uma das grandes questões levantadas para a elaboração deste trabalho, além de fornecer dados para os órgãos responsáveis, era justamente fazer com que os cidadãos cuidarem tanto das infraestruturas como da flora das cidades. Com isso a aplicação se torna uma ferramenta 
indispensável para todos. Ademais, ainda pode ser aplicado nas áreas do meio ambiente, facilitando o estudo da arborização, pois a ferramenta apresenta todos os pontos onde se encontra alguma interferência causada por ela.

A fim de testar a aplicação foram realizados diversos teste de software, tais como: teste de usabilidade, testes funcionais e teste de segurança. Objetivando aprovar as funcionalidades propostas e encontrar os possíveis erros. Dentre as dificuldades observadas, a que se esteve mais presente no escopo da implementação foi na comunicação entre a aplicação e o website, exigindo correções por parte do autor para que assim pudesse chegar aos resultados desejados.

Para realizar os testes de usabilidade foi feito um questionário contendo 6 perguntas, que foram respondidos por 20 usuários do aplicativo, sendo elas: consigo mexer no sistema sem dificuldades? O sistema previne erros? O sistema tem uma interface agradável? de fácil utilização? As funções do sistema estão muito bem integradas? Você aprendeu a usar esse aplicativo rapidamente? Você se sente confiante ao usar o sistema? A Figura 4 mostra os resultados dos testes. Além dos testes o aplicativo foi comprado com outros semelhantes.

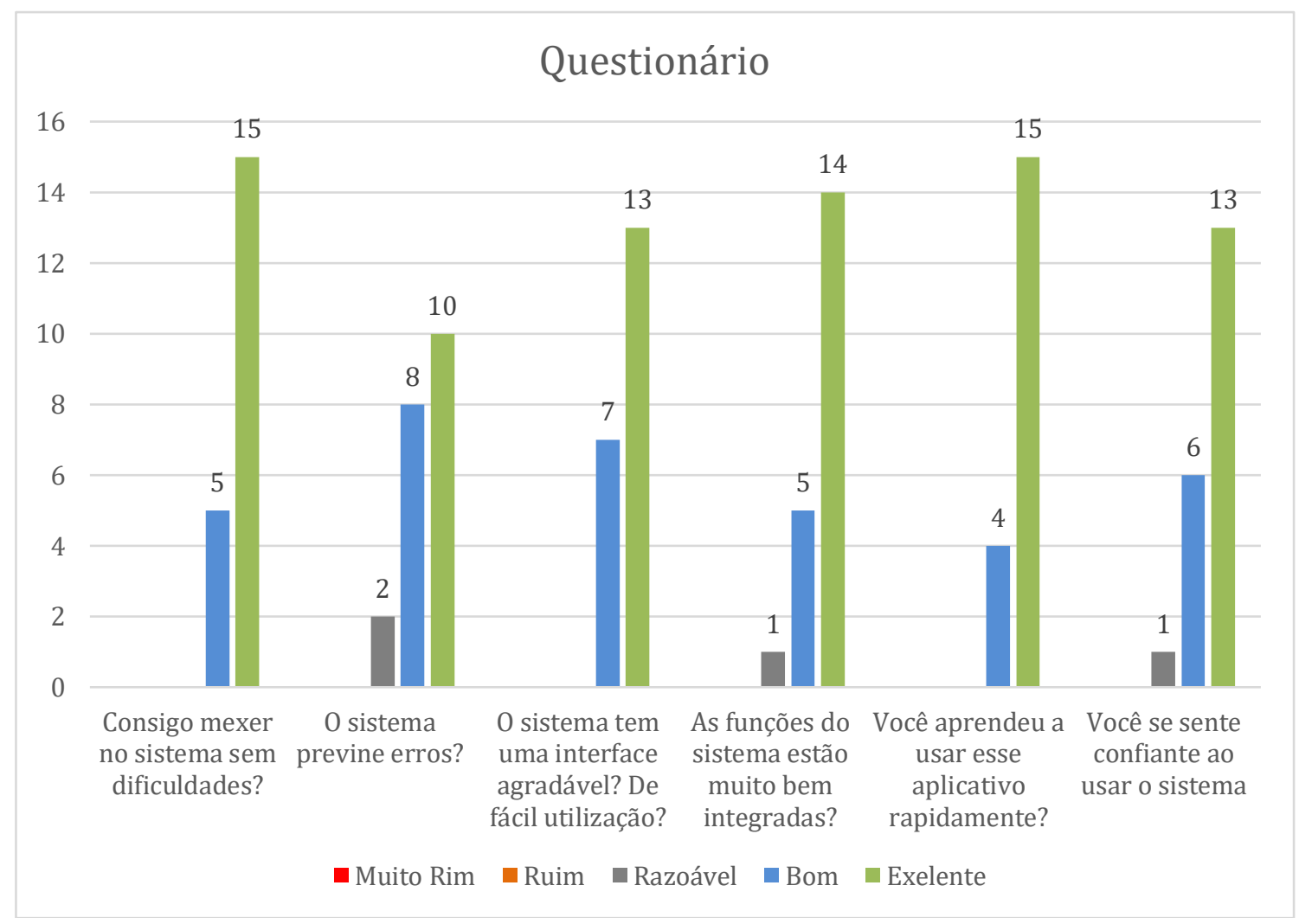

Figura 4 - Perguntas realizadas no teste de usabilidade.

A aplicação implementada por Lucena (2019) se assemelha com aplicação desenvolvida nesse artigo. Eles se distinguem nas tecnologias utilizadas, tais como o framework como nas linguagens de programação. Mas uma das principais diferenças foi a área de estudo, pois, sua plataforma foca nos problemas urbanos, e aplicação apresentada neste trabalho temos o objetivo de evidenciar principalmente nos problemas causados pela arborização.

A aplicação Pelas Ruas, é uma plataforma onde os usuários compartilham imagem e o problema detectado, que serão debatidos pelos usuários de Porto Alegre e região, já o Tree 
is Life serve como intermediário entre os cidadãos e os órgãos responsáveis, que facilita a comunicação entre os mesmos.

O aplicativo Prefeitura 360 possui algumas semelhanças com a aplicação desenvolvida nesse artigo, pois ele serve como o intermédio entre a população e a prefeitura, sobre os problemas encontrado na cidade. Entretanto, o Tree is Life se diverge a outra área de estudo e na quantidade de órgãos responsáveis, abrangendo uma maior interação de órgãos e, não somente, se limitando apenas à prefeitura, além do mesmo focar apenas nos problemas causados pela arborização urbana na infraestrutura das cidades.

\begin{tabular}{|c|c|c|c|c|}
\hline Funcionalidades & $\begin{array}{l}\text { Repórter } \\
\text { Cidadão }\end{array}$ & Pelas Ruas & $\begin{array}{l}\text { Prefeitura } \\
360\end{array}$ & $\begin{array}{l}\text { Tree is } \\
\text { Life }\end{array}$ \\
\hline Multiplataformas & $\mathrm{Sim}$ & Não & Não & $\mathrm{Sim}$ \\
\hline $\begin{array}{l}\text { Segurança dos } \\
\text { dados }\end{array}$ & Sim & Sim & Sim & Sim \\
\hline $\begin{array}{l}\text { Múltiplos } \\
\text { usuários }\end{array}$ & Não & Não & Não & Sim \\
\hline Reportar offline & Não & Não & Não & Sim \\
\hline
\end{tabular}

Tabela 1 - Diferença de recursos entre os aplicativos.

A Tabela 1 mostra a diferença de recursos entre os aplicativos. Através dos levantamentos de funcionalidades ilustrado pode-se perceber que o aplicativo possui uma significativa relevância apresentando diversas vantagens, como multiplataformas permitindo ser utilizados por diferentes sistemas operacionais (Android, IOS). e garantindo a segurança de seus dados. A aplicação permite o acesso de múltiplos usuários, ou seja, vários adeptos do aplicativo podem utilizar o mesmo dispositivo para efetuar sua respectiva reclamação. Mesmo que o dispositivo não esteja devidamente conectado a uma rede de internet.

\section{Conclusão}

Percebemos que a arborização urbana no Brasil tem sido uma preocupação constante dos ambientalistas, uma vez observados as vantagens dessa para a sociedade. Com técnica e conhecimento específicos e tecnologia é possível trazer muitos benefícios para a comunidade que recebe em suas ruas praças e avenidas um projeto de arborização urbana.

$\mathrm{O}$ aplicativo Tree Is Life realiza reclamações de interferências causadas pela arborização nas pequenas e grandes metrópoles, mostra-se de fundamental importância na preservação das infraestruturas das cidades. Após diversos testes realizados pelo autor perante o projeto, tornou-se comprovado a eficiência do sistema, chegando à conclusão de que o protótipo atende todas as funcionalidades planejadas na etapa inicial de criação.

Para trabalhos futuros, almeja-se, implementar algumas funcionalidades com o intuito de facilitar a interação do usuário, como a comunicação direta com os órgãos responsáveis sem possuir um intermédio (administrador) entre eles. Além de realização de mais outros testes de software, como a realização dos testes de performance, testes de carga 
e estresse, teste de estabilidade e teste de regressão, a fim de deixar a ferramenta cada vez mais agradável ao uso.

\section{Referências}

A ARBORIZAÇÃO urbana. 2009. Companhia Paranaense de Energia. Disponível em: https://www.copel.com/hpcopel/guia arb/a_arborizacao_urbana2.html. Acesso em: 14 mar. 2020.

API: conceito, exemplos de uso e importância da integração para desenvolvedores. 2019. Take. Disponível em: https://take.net/blog/devs/api-conceito-e-exemplos. Acesso em: 16 ago. 2020.

O que é e como usar o MySQL? 2012. Pedro Pisa. Disponível em: https://www.techtudo.com.br/artigos/noticia/2012/04/o-que-e-e-como-usar-o-mysql.html.

Acesso em: 16 ago. 2020.

GOOGLE PLAY. Pelas Ruas. 2019. Disponível em: $\leq \mathrm{https}$ ://play.google.com/store/apps/details?id=br.com.gruporbs.pelasruas\&hl=pt_BR $>$

Acesso em: 18 de novembro de 2019.

GOOGLE PLAY. Prefeitura 360. 2019. Disponível em: $<$ https://play.google.com/store/apps/details?id=com.caique.molina.prefeitura360\&hl=pt B

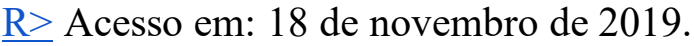

GROUP, The Php. O que é o PHP? 2020. Disponível em: https://www.php.net/manual/pt BR/intro-whatis.php. Acesso em: 14 mar. 2020.

LUCENA, Leonardo Bandeira de. REPÓRTER CIDADÃO: UM APLICATIVO HÍBRIDO PARA O RELATO E ACOMPANHAMENTO DE PROBLEMAS URBANOS. 2019. $73 \mathrm{f}$. TCC (Doutorado) - Curso de Ciência da Computação, Universidade do Estado do Rio Grande do Norte, MossorÓ - Rn, 2019. Disponível em: https://di.uern.br/tccs2019/html/ltr/PDF/015002950.pdf. Acesso em: 14 mar. 2020.

O QUE é o Flutter? 2019. Disponível em: http://clubedosgeeks.com.br/programacao/o-quee-o-flutter. Acesso em: 14 mar. 2020.

PIMENTEL, Gabriel Santos et al. APLICATIVO LÚDICO PARA CONSCIENTIZAÇÃO AMBIENTAL DE CRIANÇAS ENTRE 7 E 11 ANOS. 2018. 11 f. TCC (Doutorado) - Curso de Desconhecido, Universidade Santa Cecília - Unisanta, Santos Ps, 2018. Disponível em: http://conic-semesp.org.br/anais/files/2018/trabalho-1000001389.pdf. Acesso em: 16 mar. 2020.

PISA, Pedro. O que é e como usar o MySQL? 2012. Disponível em: https://www.techtudo.com.br/artigos/noticia/2012/04/o-que-e-e-como-usar-o-mysql.html.

Acesso em: 14 mar. 2020.

QUEIROZ, Danilo Oliveira de. PLANT MAP PALMAS: APLICATIVO EM PLATAFORMA MÓVEL PARA LOCALIZAÇÃO DAS ÁRVORES FRUTÍFERAS E MEDICINAIS NA ÁREA URBANA DE PALMAS-TO. 2018. 22 f. Dissertação (Mestrado) - Curso de Programa de PÓs-graduaÇÃo Modelagem Computacional de Sistemas, Universidade Federal do Tocantins Campus UniversitÁrio de Palmas, Palmas-to, 2018. Disponível

em: http://repositorio.uft.edu.br/bitstream/11612/1222/1/Danilo\%20Oliveira $\% 20$ de $\% 20$ Queiroz \%20-\%20Disserta\%c3\%a7\%c3\%a3o.pdf. Acesso em: 16 mar. 2020. 